\title{
Economia criativa: entre a moda e o artesanato
}

Salete Nery ${ }^{1}$

Resumo: De acordo com as categorizações do MinC, a moda é setor da economia criativa e, pois, deve ser alvo de ações governamentais. Por outro lado, em debate de abertura do São Paulo Fashion Week (SPFW), Armand Hadida afirmou que o artesanato nacional, igualmente setor da economia criativa, seria o elemento de criatividade para uma produção de moda brasileira com possibilidade de inserção internacional. Tomando-se esses dois fatores, busca-se discutir a relação entre os setores moda e artesanato, a partir do modo como o artesanato tem sido utilizado por criadores de moda e, portanto, como têm sido estabelecidas as relações entre estilistas e grupos de artesãos na composição de produtos singulares para comercialização nacional e internacional.

Palavras-Chave: moda, artesanato, designers de moda.

\begin{abstract}
According to the MinC's categorizations, fashion is a creative industrial sector, therefore it should be subject to government actions. Moreover, in Sao Paulo Fashion Week's opening debate (SPFW), Armand Hadida stated that the national handicrafts, equally recognized as an economic creative sector, would be the component of inspiration to the production of Brazilian fashion with the possibility of international integration. By taking these two factors into consideration, it is analyzed the relationship between fashion and handicraft sectors, from the way the craft has been used by fashion designers and thus how the relationships among groups of designers and crafters have been established within the composition of singular products for national and international marketing.
\end{abstract}

Key Words: Fashion, handicrafts, designers

\section{Introdução}

A percepção de que a cultura se transforma, a cada dia, em excelente negócio não nasce no Brasil. Segundo dados divulgados pelo Banco Mundial, a cultura ajuda a produzir cerca de $7 \%$ do Produto Interno Bruto (PIB) global. O governo britânico, inclusive, deu um passo significativo ao criar o Ministério das

\footnotetext{
${ }^{1}$ Professora Adjunta da Universidade Federal do Recôncavo da Bahia (UFRB) e pesquisadora do Grupo de Pesquisa Cultura, Memória e Desenvolvimento (UnB).
}

Latitude, vol. 6, n², pp.221-239, 2012

DOI: https://doi.org/10.28998/2179-5428.20120208 


\section{Economia criativa: entre a moda e o artesanato}

Indústrias Criativas. No caso brasileiro, não havia dados que revelassem a relação entre cultura e dinheiro, na nação. Em vista disso, o Ministério da Cultura encomendou ao IBGE (Instituto Brasileiro de Geografia e Estatística) uma pesquisa que permitisse perceber o peso da cultura na economia nacional. Em novembro de 2006, enfim, dados acerca do consumo de cultura no país foram divulgados, tendo como referência os anos de 2003 e 2004. O objetivo do então Ministro Gilberto Gil, além de incentivar a profissionalização nas diferentes etapas do ciclo de produção, distribuição, divulgação e comercialização da cultura, como uma mercadoria a circular no Brasil e também em outros países, era iniciar a construção de dados que permitissem conhecer e avaliar o PIB da cultura no país; isto é, dados mais precisos acerca do que significa a "cara da cultura" e seus impactos na economia brasileira.

No que se refere, no entanto, às informações apresentadas pelo IBGE em fins de 2006, destaca-se, em primeiro lugar, que a cultura figurava em quarto lugar no que se refere ao consumo do brasileiro, inferior apenas a habitação, alimentação e transporte, e superior a vestuário, educação, dentre outros. A cultura mobilizava, de acordo ainda com tais dados, aproximadamente $8 \%$ do orçamento familiar brasileiro. A média mensal de despesa com cultura ficou em torno de $\mathrm{R} \$ 115,50$ (dado corrigido pelo IPCA, Índice Nacional de Preços ao Consumidor Amplo). “Os gastos culturais variam de despesas com decoração, reprodução de materiais gravados e aquisição de eletrodomésticos, como serviços de tv por assinatura e internet, cinema, teatro e show, discoteca, festas, aniversários e casamentos, além de cursos" (SPITZ, 2006).

A pesquisa realizada pelo IBGE, como lidou com dados de outras pesquisas, como a de Orçamentos Familiares, para compor o panorama apresentado, teve sérias dificuldades na realização de sua encomenda. A noção de cultura utilizada teve de ser consideravelmente ampla e, além disso, teve que incluir dados que apenas indiretamente se referem à cultura. Por exemplo, os computadores são um meio através do qual se pode ter acesso a bens chamados culturais, mas em que medida isso ocorre não pôde ser mensurado. O mesmo se dá quanto à telefonia, ao comércio atacadista de artigos de escritório, papelaria, dentre outros. Ainda assim, o perfil apresentado merece consideração como um ponto de partida à avaliação do papel da cultura no país e à estruturação de políticas públicas voltadas ao setor. É nesse sentido que, no Governo Dilma Roussef, é criada a Secretaria da Economia Criativa como nova pasta do Ministério da Cultura, este capitaneado ainda pela Ministra Ana de Hollanda.

Como trabalho inicial, houve a apresentação, pela secretaria, do plano de gestão para o período de 2011 a 2014. No referido Plano da Secretaria da Economia Criativa (2011-2014) é problematizado e sistematizado o que significa economia criativa em âmbito brasileiro e sua estrutura, organizada em categorias e setores culturais, em compasso com as discussões realizadas pela UNESCO e pela Conferência das Nações Unidas para Comércio e Desenvolvimento (UNCTAD). 
Seguindo os princípios da inclusão social, sustentabilidade, inovação e diversidade cultural brasileira, busca-se ultrapassar uma visão meramente economicista da cultura e ressaltar o simbólico como dimensão determinante dos bens, cujos produtos são de "riqueza cultural, econômica e social" (MINC, 2011, p. 22). Por outro lado, tem-se a tácita indicação de que a identidade nacional pode ser tomada como importante chave para valorização das produções nacionais, em sua diversidade, e para uma mais ampla aceitação do produto brasileiro no mercado internacional. A partir daí, busca-se apresentar as diretrizes, políticas e ações no que se refere à economia criativa brasileira, o que inclui, sem dúvidas, a produção de pesquisa com dados mais sólidos acerca da criação, produção, distribuição/circulação/difusão e consumo/fruição desses bens, bem como dos desafios a serem enfrentados para dinamização do campo.

O momento atual, portanto, guarda uma série de especificidades. O empenho com que não apenas o governo britânico, mas tantos outros, a exemplo do próprio Brasil, têm tido em firmar suas produções culturais num mercado global esbarra na necessidade e tentativa de diminuição do ranço impetrado quanto à relação entre cultura e dinheiro. A expressão economia da criatividade, entendida como mais adequada do que a de indústria da criatividade, parece ser uma tentativa de diminuir o tom pejorativo com que é marcada tal associação. É digno de nota o tom pejorativo com que os teóricos da chamada teoria crítica, a exemplo de Adorno e Horkheimer, empregaram o termo indústria cultural no sentido de denunciar a transformação da cultura num bem massificado, ou seja, produzido em conformidade com as leis perversas do capitalismo. Por outro lado, se dentro das ciências sociais há uma série de indefinições no que toca às noções de cultura e de arte, ainda alvos de intensos e acirrados debates, o mesmo não pode se dar quanto à definição de políticas e ações implementadas pelo Ministério dedicado à Cultura. O que compõe a cultura, do ponto de vista do governo brasileiro? Sem dúvida, o estabelecimento de definições precisas foi um dos principais desafios enfrentados para a constituição do plano de primeira gestão da Secretaria da Economia Criativa². Responder a tal questão ajuda, inclusive, a interpretarmos os dados apresentados pelo IBGE, juntamente com o MinC (Ministério da Cultura). Por exemplo, em abril de 2007, durante um evento de moda, o então Ministro da Cultura, Gilberto Gil, elevou a moda ao status de cultura. Os dados, já citados, apresentados em 2006, consideravam a moda como um âmbito à parte em relação à cultura: a produção e o consumo de moda não

\footnotetext{
2 "Definimos Economia Criativa partindo das dinâmicas culturais, sociais e econômicas construídas a partir do ciclo de criação, produção, distribuição/circulação/difusão e consumo/fruição de bens e serviços oriundos dos setores criativos, caracterizados pela prevalência de sua dimensão simbólica" (MinC, 2011, p. 23).
} 


\section{Economia criativa: entre a moda e o artesanato}

foram considerados na construção dos dados, sendo, inclusive, considerado que o consumo de bens culturais teria sido superior ao consumo de moda.

Segundo Enrique Saraiva (2011), foi por conta de necessidades econômicas e políticas que a moda foi incorporada, no Reino Unido, ao rol da economia criativa, o que não teria se dado, conforme o autor, de modo tranquilo. No que respeita às definições apresentadas pelo MinC, a moda hoje figura como um dos setores criativos que compõem as criações culturais funcionais - junto ao design e a arquitetura. Por sua vez, a definição de setores criativos aponta a criatividade e, pois, o valor simbólico dos bens como determinantes de sua classificação no âmbito da economia criativa, o que, a rigor, possibilita a inclusão da moda como setor criativo.

O objetivo deste trabalho, no entanto, não se centra na problematização da moda enquanto setor criativo e, portanto, alvo dos interesses e políticas governamentais, o que levaria ao debate acerca, inclusive, dos modos sociohistoricamente construídos de categorização e valoração da moda sob os pontos de vista da cultura/arte e do negócio. Em junho de 2010, na programação de abertura do SPFW (São Paulo Fashion Week), maior evento de moda da América Latina, que congrega desfiles, conferências e feira de negócios, o debate se centrou na discussão a respeito da relação entre moda e economia criativa. Nessa ocasião, segundo Glória Kalil (2010), consultora de moda, Armand Hadida, dono da lojaconceito parisiense L'Éclaireur, teria apontado o artesanato brasileiro, em um "uso renovado", como principal e pouco explorado vetor de criatividade para uma produção nacional diferenciada e sua inserção no mercado exterior. De acordo com as categorizações do MinC, o artesanato figura como um dos setores da categoria cultural de expressões culturais. Uma vez que os produtos criativos podem ser, em geral, classificados em mais de um segmento criativo, buscamos, neste trabalho, discutir a relação entre os setores moda e artesanato, problematizando a relação criatividade, negócio, desenvolvimento e responsabilidade social. Mais especificamente, tomamos os modos como o artesanato tem sido utilizado por criadores de moda e, portanto, como têm sido estabelecidas as relações entre estilistas e grupos de artesãos na composição de produtos singulares para comercialização, em mercado nacional e internacional.

Este artigo parte da construção de uma tipologia das trajetórias de artesãos têxteis (de roupas) a partir de seus mecanismos de inserção na malha de negócios vinculados à moda dentro e fora do país. Esses tipos envolvem tanto os grupos de trabalhadores que se mantiveram em seus lugares de origem, quanto aqueles que se deslocaram em busca de inserção. A interpretação dos tipos é feita a partir de casos exemplares que ilustram e, ao mesmo tempo, ajudam a problematizar a questão do comércio (produção e consumo) de artesanato têxtil em sua relação com a moda, no país, seja considerando o fluxo de gente ou de coisas como 
determinante da inserção no mercado de moda. Analisar tais trajetórias e seus resultados é feito através de casos que exemplificam os tipos.

O primeiro desses tipos é o da artesania de segunda ordem, discutido a partir do caso de uma artesã de Maceió que passou a comprar tecidos de renda de rendeiras do interior de Alagoas, a partir dos quais ela elabora suas próprias produções artesanais. Essa artesã mantém ateliê e loja em Maceió e, hoje, também em São Paulo, comercializando nacional e internacionalmente. Temos aí a trajetória dessa artesã e do grupo de rendeiras que se mantiveram no interior do Estado e que comercializam seu produto, por encomenda, para ela. O segundo caso é de uma família pernambucana que inicia produção familiar e abre estabelecimentos comerciais em diferentes aeroportos do país (artesanato empresarial familiar). O terceiro caso, por sua vez, é de um artesão do Mato Grosso do Sul que aprende os inícios do ofício em ambiente doméstico e resolve burilar seus conhecimentos na Inglaterra (artesanato profissional). O quarto caso é de um grupo de rendeiras do interior da Bahia, que mantém a prática de comercializar para os turistas da região e gente local e, mais recentemente, criou uma cooperativa para ampliar os negócios (artesanato por associação ou cooperativas). A partir da análise desses casos e tipos espera-se compreender os rumos do artesanato têxtil no Brasil em função de sua relação com a moda e com o processo de integração nacional, e suas consequências.

Para efeitos deste específico trabalho, busca-se, a partir do caso Martha Medeiros, estilista de Maceió (Alagoas), que tem nos trabalhos com renda entendida como tradicional a base de seus trabalhos, problematizar a questão da produção-consumo de artesanato têxtil no Brasil em função da temática das políticas públicas voltadas à integração nacional e integração do Brasil na rede globalizada de negócios em moda. O caso em questão se mostra interessante na medida em que, como será evidenciado, nos permite articular diferentes ordens (tipos) de trabalho artesanal numa mesma teia configuracional.

Discutir, hoje, a produção artesanal têxtil no Brasil significa envolver-se num denso e diversificado novelo de questões. Se, por um lado, o consumidor dos bens artesanais têxteis, entendido como aquele com potencial para dinamizar o setor, está referido a grupos de estilo vinculados à intelectualidade, à vanguarda e àqueles que buscam o diferente, em comparação com o industrializado - isto é, sobremaneira grupos que residem nas grandes urbis dentro e fora do Brasil -, o produtor desses bens, no que toca ao Brasil, especificamente, ainda pode ser caracterizado como o indivíduo que reside nas cidades e regiões periféricas do país e que tem, no artesanato, uma atividade familiar e secundária de complementação da renda doméstica ${ }^{3}$.

\footnotetext{
${ }^{3}$ Ainda que o Programa do Artesanato Brasileiro (PAB), iniciativa do Governo Federal com vistas a, principalmente, incentivar o associativismo e a constituição de cooperativas, tenha tido início a partir de decreto de 1995.
} 


\section{Economia criativa: entre a moda e o artesanato}

Em outros termos, a distância geográfica marca esse tipo de relação, como se tivéssemos tratando de um mundo ou época anterior às discussões sobre desencaixe tempo-espaço, encurtamento das distâncias, simultaneidade, velocidade, pelo modo como essa distância espacial marca ainda a ordem das relações estabelecidas, no que tange ao artesanato têxtil. Em outros termos, a aproximação se dá, em grande medida, pelas viagens dos turistas e sua busca pelo exótico, do qual o artesanato têxtil faria parte como objeto privilegiado, ou pela aventura dos artesãos mais corajosos em seu deslocamento para os grandes centros, em busca de oportunidades maiores. As ligações que permitiriam a proximidade entre os distantes ainda é caracterizada pela precariedade. No entanto, podemos perceber mecanismos diversos, historicamente construídos, de aproximação, ao mesmo tempo em que mudanças mais recentes têm se processado em decorrência de medidas governamentais de diminuição dos desequilíbrios entre as regiões brasileiras em função de uma maior integração nacional.

Mesmo ao tomarmos a moda em sentido mais amplo, somos obrigados a perceber o quão recentes são as medidas que conferiram maior viabilidade ao setor como negócio. Em julho de 1996, foi realizada a primeira edição do Morumbi Fashion Brasil, calendário Oficial de Moda, projeto de Paulo Borges e evento precursor do SPFW. E, no mesmo ano, tem-se a realização da Semana BarraShopping de Estilo, no Rio de Janeiro, projeto idealizado pela Dupla Assessoria, empresa de produção de eventos de moda (GERALDINI, 2008). Os anos 1990 marcam, por um lado, as consequências do Plano Collor de abertura do mercado brasileiro aos produtos estrangeiros, mais baratos e de melhor qualidade em relação ao produto nacional, o que levou à profissionalização forçada daqueles que conseguiram "sobreviver" à concorrência desigual; e, por outro, as primeiras consequências do Plano Real de estabilização da economia.

Segundo Paulo Borges, no entanto, as dificuldades em organizar o Calendário Oficial de Moda foram inúmeras, pois envolviam reunião de pessoas e empresas importantes ao setor, mas que pouco dialogavam, num mesmo evento. $\mathrm{O}$ funcionamento da moda, pensada como indústria, envolve a necessária articulação entre diversos setores de produção que, no Brasil, ainda mantinham desenvolvimento à parte do restante da cadeia produtiva. A proposta de um calendário da moda significava a tentativa de criar um espaço e um momento que servisse também ao estabelecimento de relações e negócios entre os diferentes segmentos atomizados, ao mesmo tempo em que se incrementava o potencial de visibilidade dos diferentes setores e profissionais devido à sua concentração em evento único. Tratava-se de momento propício ao desenvolvimento de carreiras ligadas ao setor e à efetivação de negócios de vulto.

Outra mudança significativa para a profissionalização da moda no Brasil teria sido o trabalho da ABIT, Associação Brasileira da Indústria Têxtil e de Confecção, também em fins dos anos 1990, no sentido de promover a união entre 
produção de algodão, fiação, tecelagem, malharia e confecção através da criação de metas comuns a todos e específicas a cada área de modo a modernizá-las e integrálas. A ação mais efetiva da ABIT é a criação, em 1997, da Agência de Promoção de Exportação e Investimentos (Apex-Brasil), ligada ao Ministério do Desenvolvimento, Indústria e Comércio Exterior. Os resultados obtidos por esses novos eixos de articulação impulsionaram a fundação, em 2003 (ano de eleição do Presidente Luiz Inácio Lula da Silva), da Associação Brasileira de Estilistas (Abest), por iniciativa dos estilistas Alexandre Herchcovitch, Amir Slama, Lino Villaventura, Serpui Marie e Walter Rodrigues. A Abest surgiu da dificuldade que os estilistas enfrentavam especialmente para exportar suas produções. O objetivo da Associação é, nas palavras de Herchcovitch, "obter maiores incentivos do governo brasileiro no quesito exportação" (2007, p. 75). Assim, a inserção da moda como setor da economia criativa acaba por incrementar tais iniciativas. Atualmente a Abest, sob a presidência de Valdemar Iódice, conta com 55 grifes.

Em 2003, a entidade exportou US\$ 3 milhões em vendas, em 2006 houve um salto para US\$ 12 milhões e no ano de 2011 a ABEST conquistou o expressivo valor de mais de US\$18,3 milhões, com exportação para 66 países. Considerando as iniciativas promovidas, no último ano houve um investimento de $\mathrm{R} \$ 5,5$ milhões em projetos como desempenhos em desfiles, showrooms, feiras e outras iniciativas.

Todas as ações promovidas pela ABEST tem como objetivo a propagação mundial da moda brasileira, ampliar a penetração em novos mercados e estreitar relações com os já conquistados. Através deste trabalho a moda brasileira já é vista como criativa, inovadora, e profissional. (WWW.abest.com.br).

Atualmente, a Abest conta com a parceria e convênio da Apex-Brasil, do Desenvolve SP, do Ministério do Desenvolvimento, Indústria e Comércio Exterior e do Serviço de Apoio às Micro e Pequenas Empresas (SEBRAE). São ações conjugadas que têm envolvido as diferentes relações que compõem a configuração da moda dentro do Brasil e, assim, profissionalizando as relações, cria-se a base para a crescente inserção competitiva no mercado internacional de moda. Contudo, é fundamental pontuar uma mudança significativa no modo como os próprios estilistas passaram a conceber a moda e a gerir seus negócios particulares. A mais vigente concepção de moda como arte (desinteressada das questões econômicas, postas em segundo plano) acabava por ensejar uma relação de descuido por parte de muitos criadores quanto às questões administrativo-financeiras das casas de costura, função que, normalmente, era por eles abarcada. $\mathrm{O}$ movimento de expansão global dos negócios em moda, todavia, com o incremento tecnológico que ocorre em diferentes lugares do mundo, implica o contramovimento simultâneo que permite a tímida incursão dos criadores brasileiros na dinâmica internacional dos negócios ligados à moda, mesmo em condição periférica. $\mathrm{Na}$ esteira de tais transformações, os estilistas se rebatizam, no anos 1990, de diretores de criação, evidenciando sua nova relação com o trabalho e os meandros da 


\section{Economia criativa: entre a moda e o artesanato}

complexa cadeia de produção de moda. Não havia mais espaço para o costureiroartista: a partir daí criador e administrador se conjugam de forma mais profissional ou se desmembram em função da constituição de equipes de trabalho, a partir da concepção de que moda é negócio e, portanto, deve ser gerida como tal.

Um dos movimentos, nesse sentido, que começa a proliferar inicialmente na Europa dos anos 1980, e no Brasil, a partir dos 2000, é a aquisição, por holdings e fundos de investimento, de várias grifes destinadas a distintos públicos, sob uma administração comum e com específicas direções criativas, associando o trabalho de administradores e estilistas, agora figuras distintas. A mais rígida distribuição de funções e a assunção do caráter de funcionário de uma rede é relativamente recente no que toca Ao ofício de criador de moda. A racionalização da gestão e a maior capacidade de investimento como motor à expansão dos negócios, num difícil mercado globalizado seria a principal justificativa às aquisições. O interesse do criador na condução da empresa é mantido a partir do momento em que ele se mantém no negócio na condição de sócio, o que lhe garante certa margem de autonomia e poder de decisão quanto a deliberações que dizem respeito à empresa e que são definidas como de sua competência, através de contrato. Em outros termos, a função de diretor de criação aponta para um específico formato de gestão, em que tal profissional assume a coordenação de uma equipe no que toca à criação de peças, ou seja, dentro de uma empresa marcada por acentuada especialização de tarefas. Criação e administração se transformam em segmentos distintos na condução dos negócios da moda, um formato recente na história do vestuário. Contudo, tais iniciativas e transformações rumo à moda-negócio só foram possíveis no Brasil após medidas governamentais de integração interna (do país) e externa (no mercado global) que permitiram, ainda que precariamente, maior circulação dos indivíduos, de produtos e de informações, sem o qual um mercado nacional e internacional de moda seria de difícil estabelecimento.

\section{Do fluxo de gente ao fluxo de coisas}

De acordo com Santos e Silveira (2006), ao analisarmos o século XX, podemos perceber um esforço no sentido de viabilizar a integração brasileira, contudo, a história nacional é marcada por grandes disparidades regionais, que levaram a um desequilíbrio populacional e de negócios dentro do país. Deste modo, dois caminhos são possíveis para o estabelecimento e desenvolvimento dos negócios de moda em torno do artesanato têxtil: 1) o do fluxo de gente, seja do produtor em busca das regiões e cidades mais desenvolvidas do país, seja do consumidor, em suas viagens, em direção às regiões mais periféricas; 2) o do fluxo de coisas, pela constituição de mecanismos que possibilitem que as mercadorias circulem e que, portanto, o produtor e o consumidor não precisem necessariamente se deslocar. Independente do caminho trilhado, o papel governamental é 
fundamental na criação das condições para a mobilidade de gente e de coisas dentro de um país, em especial quando se deseja a integração desse país à rede internacional de negócios. No entanto, as políticas de integração nacional visaram, por excelência, o desenvolvimento industrial, o que contribuiu, e contribui, para que o artesanal permaneça à reboque e, portanto, refém desses processos sem que o produtor de bens artesanais fosse efetivamente inserido na "construção do Brasil desenvolvido" - e isso, em grande medida, devido ao artesanal, mesmo considerado produto típico, ser identificado ao atraso, ao passado, ao estanque, ao de pouco rendimento e, pois, de parco interesse.

A necessidade de ampliação do mercado para essa industrialização em desenvolvimento levou à extinção das barreiras à circulação de produtos entre os Estados da União, já desde os anos 1930 da política Vargas, contribuindo para a promoção, incipiente, da integração nacional; no entanto, no período, faltava, ainda, a estruturação de uma malha nacional de transportes (SANTOS, SILVEIRA, 2006). Com evidentes desigualdades regionais, a concentração do desenvolvimento e a posição assumida por São Paulo nesse processo, acabou estimulando um fluxo migratório crescente dentro do próprio Brasil, em especial advindo do Norte e Nordeste, e que tinha no citado Estado um de seus principais destinos. É, portanto, apenas no período que vai do começo do século XX aos anos 40 que começa, segundo os autores, a se dar um esboço de integração nacional, com a construção das estradas de ferro e aparelhamento dos portos.

É igualmente nesse período que começa a melhor se delinear a hegemonia paulista, "com o crescimento industrial do país e a formação de um esboço de mercado territorial localizado no Centro-Sul" (p. 37). Nesse mesmo período, o número de imigrantes brasileiros para o Estado de São Paulo passa a superar o de estrangeiros. Devido às disparidades de renda no Brasil e à grande concentração da produção e do consumo no Sudeste, as estratégias de produção nacional se voltam crescentemente ao mercado externo e suas demandas, o que aumenta a necessidade de modernizar as indústrias nacionais. A circulação entre as diversas regiões e destas com a chamada "região concentrada", noção de Milton Santos, mesmo que com densidades diversas, é ainda mais facilitada. A difusão de energia elétrica, antes localizada, passa a compor uma rede nacional a partir da criação e atuação da Eletrobrás, nos anos 1960. Ao mesmo tempo, uma revolução das comunicações ocorre nos anos 1970 com o uso de satélites. Vivia-se o chamado "milagre brasileiro", período de franca expansão nos negócios, que ajudou a substituir a antiga camada abastada do Brasil. Ao mesmo tempo, amplia-se a capacidade de compra do brasileiro, guardando aí as diferenças regionais, fazendo com que indivíduos de camadas mais pobres comecem a gastar mais em chamados bens supérfluos, não apenas dinamizando o setor do comércio de moda, mas conferindo específico acento nas produções industrializadas, os prontos-para-usar, 


\section{Economia criativa: entre a moda e o artesanato}

que começam a melhorar sua qualidade e a rivalizar com o domínio dos estilistas dedicados à roupa sob medida.

No Brasil, os anos 1970 iniciaram ainda sob o embalo do "milagre brasileiro" (1968-1973), contudo a crise do petróleo, em fins de 1973, e as condições da empresa privada nacional, com uma burguesia nascente e comprimida por dois grandes gigantes, as estatais e as multinacionais, conferiam grande privilégio ao produto importado. A política neoliberal defendida pelos Estados Unidos preconizava a abertura do mercado de chamados países de Terceiro Mundo para a livre concorrência com empresas estrangeiras, em melhores condições que as empresas desses países, alguns deles recém-saídos da condição colonial. Em situação privilegiada, as empresas, em especial norte-americanas, começaram sua incursão em diferentes países criando uma rede de extensão ainda maior e que abarcava os diferentes continentes, mas em relações de assimetria evidentes. O Brasil entra nesse circuito na condição de dependente e subalterno, uma vez que os investimentos nas empresas privadas nacionais eram pautados, sobretudo, em financiamentos externos ou estatais; sendo estes também via empréstimos no exterior. Constrói-se uma dívida externa que implica diminuição dos investimentos internos e o afluxo de dinheiro para pagamento da dívida, que, em contexto de crise internacional, começa a ser cobrada, ao mesmo tempo em que diminuem as possibilidades de empréstimo.

Tal situação se agrava nos anos 1980. De qualquer modo, modelo similar de desenvolvimento desigual de integração é perceptível também dentro do Brasil com as evidentes discrepâncias regionais e centralidade, não apenas na produção de moda, das capitais São Paulo e Rio de Janeiro. No entanto, numa economia globalizada, a estruturação de um sistema financeiro eficiente torna-se condição ao desenvolvimento de negócios de solidez, e, no Brasil, São Paulo ganha dianteira nesse processo frente ao Rio de Janeiro e aos demais Estados do país. A Embratel, criada em 1965, acabou por liderar o processo de informatização, facilitando a integração ao mercado globalizado e contribuindo para a expansão da quantidade de empresas, no setor de informática. Nos anos 1970, tem-se a criação da Embrapa, que irá, por seu turno, promover pesquisas que contribuirão para o desenvolvimento da indústria têxtil. O relativo movimento de desconcentração da produção industrial brasileira que ocorre nos anos 1970, num espelhamento do que já ocorria desde os anos 1930 e internacionalmente com a aceleração do processo de globalização, favorece, neste momento, o Sul do Brasil. Holdings nacionais e globais também irão se instalar, mantendo seus centros de comando no Sudeste, Sul e, por vezes, na Bahia (SANTOS, SILVEIRA, 2006).

As competições entre Estados, então, se acirram para abrigar novas fábricas. As relações significativas não estão necessariamente próximas, como ocorria anteriormente, daí a substituição, segundo Santos e Silveira, da noção de circuitos regionais de produção para a de circuitos espaciais da produção, num movimento 
comandado hoje, ainda em conformidade com os autores, por um fluxo não restrito a materiais, pois envolve capitais, informações e mensagens, cujas formas de circulação dependem da integração do sistema de comunicação e informática que possibilita a dinamização do sistema financeiro, inclusive na instituição do sistema de crédito ao consumidor como forma de efetuação de transações - o que se consolida no Brasil efetivamente nas décadas posteriores. De qualquer modo, é importante ratificar, apesar da relativa descentralização, as assimetrias permanecem.

São Paulo, metrópole brasileira, já não tem o seu papel metropolitano definido por ser uma capital industrial, mas por ser uma capital relacional, o centro que promove a coleta de informações, as armazena, classifica, manipula e utiliza a serviço dos atores hegemônicos da economia, da sociedade, da cultura e da política. Por enquanto, é São Paulo que absorve e concentra esse papel no poder decisório. (SANTOS, SILVEIRA, 2006, p. 210).

Em suma, uma das consequências de tamanhas desigualdades históricas é a migração de indivíduos das regiões menos favorecidas rumo aos grandes centros decisórios e de negócios no país, ampliando os desequilíbrios de poder e de gente entre as regiões - uma vez que as "grandes capitais" se tornam, em geral, as cidades de maior densidade populacional. Por outro lado, mesmo que apontemos as transformações geradas por tais medidas de integração, pouco houve de mudança no que se refere à produção artesanal "tradicional" no país, o que vem se reestruturando, muito lentamente, há apenas pouco tempo. Se os rumos da integração nacional favoreceram o aumento da concentração de gente e de poder econômico em cidades como São Paulo, o modo como se deu historicamente a produção artesanal no país acaba quase banindo essa atividade aos rincões mais afastados dos centros decisórios do país.

Por um tempo, bordar e costurar eram ensinamentos obrigatórios às mulheres das diferentes camadas socioeconômicas, mas a relação de tais atividades com um modo de obtenção de renda mais evidente era restrito às camadas mais pobres. Além disso, com o avanço da industrialização, as atividades manuais acabaram perdendo espaço, sendo relegadas à condição de exótico e de, pois, consumo eventual. Em outros termos, artesanato e regiões interioranas, empobrecidas, passam a figurar como quase sinônimos, apesar de, na história nacional (a exemplo dos anos 70), se apresentarem momentos de maior interesse no consumo e produção de artesanato têxtil. É assim que, se a industrialização avança no Sudeste-Sul como símbolo de progresso, o artesanato se mantém como costume, vínculo com o passado e se mantém quase confinado no Norte e Nordeste. As consequências do estreitamento das relações internacionais, num aparente paradoxo, contribuem mais recentemente para reavivar o interesse nos bens artesanais, compreendidos como autênticos, por um lado, e, por outro, como produtos diferenciados pela dedicação que exigem de seus produtores, o que os 


\section{Economia criativa: entre a moda e o artesanato}

vincula ao mundo dos bens seletos, de luxo. No entanto, fazer parte da rede que confere elevado valor simbólico e econômico ao artesanato acabava por demandar, em grande medida, o deslocamento dos indivíduos criadores de bens artesanais para a região concentrada. A visibilidade e notoriedade dependiam intimamente de articulações que passavam necessariamente pelo "Centro" do país e requeriam, pois, produtos de qualidade e também habilidade para o estabelecimento de relações vantajosas por parte daqueles que desejavam maior rentabilidade com a comercialização de seus produtos. $\mathrm{O}$ momento atual do processo de integração nacional, porém, parece ser marcado pela tentativa de contribuir para a fixação das gentes em seus locais de origem pelo favorecimento do fluxo das mercadorias, da informação e do crédito, que permite que as articulações e, pois, transações comerciais sejam estabelecidas sem contato pessoal direto, a exemplo da Rede Asta, "primeira rede de venda de artesanato pelo sistema de catálogo" (LUMA, 2011, p. 67).

Se o centro decisório permanece sendo São Paulo, por excelência, e se as desigualdades regionais se mantêm, percebe-se o aumento do fluxo migratório invertido com o crescimento de cidades de interior, em função de uma série de investimentos governamentais que visam refrear o inchaço dos grandes centros urbanos. No que se refere ao artesanato, a ampliação da rede nacional parece insuficiente para permitir participação efetiva de grupos produtores de bens artesanais, devido às características predominantes desses grupos, a exemplo do menor acesso à rede de computadores ou mesmo a informações cruciais que os possibilitem se inserir na rede de fluxo de mercadorias sem que eles próprios precisem transitar e, portanto, se deslocar para a "região concentrada". É nesse sentido que principiam os esforços para a criação de "nódulos" de articulação entre os locais mais distantes e os grandes centros.

Tais nódulos, que mantêm seu gerenciamento nas regiões concentradas, funcionam como conectores que intermediam e mesmo incentivam as ligações. Esses conectores é que teriam a função de se deslocar para o estabelecimento dos elos e para a criação das condições iniciais à participação na rede. São, por exemplo, agentes da cultura (das coordenadorias estaduais do artesanato $^{4}$, de ONGs vinculadas à economia solidária, núcleos criativos de profissionalização, SENAC e mesmo as universidades) que mantêm proximidade com esses artesãos e os instrui quanto aos rumos para participar da rede de fluxo de mercadorias sem que eles necessitem transitar junto com elas, a não ser ocasionalmente, e aumentem sua renda, contribuindo para o desenvolvimento de suas regiões de origem pela valorização da produção local e preservação de costumes e da memória de um fazer que é intergeracionalmente constituído. Essa mesma estratégia de inserção é

\footnotetext{
${ }^{4}$ Por exemplo, na Bahia o Instituto Mauá funciona como coordenadoria estadual do artesanato.
} 
também perceptível internacionalmente, com a instituição de agentes que viajam em busca de estabelecer negócios com grupos sediados em países e regiões menos desenvolvidas. Nisso, diferentes tipos de trajetórias se consolidam quando tratamos do trabalho artesanal no Brasil e com diferentes resultados para seus produtores, uma vez que estamos longe de poder negar as desigualdades regionais brasileiras.

O governo do Presidente Luís Inácio Lula da Silva (2003-2010) e o princípio do governo Dilma Roussef (2011-) marcam os esforços por constituir um terceiro momento do processo de integração nacional, ou seja, das tentativas em diminuir as desigualdades entre as regiões do país pela maior inserção das regiões marginais/marginalizadas, refreando o êxodo dessas regiões. Diferentes estratégias são voltadas à criação de condições que permitam e estimulem a permanência desses indivíduos em seus locais de origem e mesmo o realocamento de indivíduos dos grandes centros para cidades de médio e pequeno porte e para essas regiões, num fluxo migratório invertido. Essas condições se referem tanto à criação/expansão de infraestrutura básica (como o Programa Federal Luz para Todos), incentivos para alocamento de indústrias (com dedução de impostos), provimento de cargos por concurso público, interiorização de universidades e centros tecnológicos e medidas de incentivo à autossustentabilidade econômica, como, por exemplo, o Programa Economia Solidária, dentro do Programa Federal de Aceleração do Crescimento (PAC). $\mathrm{O}$ objetivo, pois, se centra no desenvolvimento social e no crescimento econômico, com redistribuição populacional e de renda no país ao se criar um quadro nacional mais equilibrado, mesmo que ainda bastante desigual.

O artesanato, enquanto atividade laboral de muitas famílias, se torna um dos caminhos para esse intento, na medida em que se supõe que a profissionalização dos artesãos possibilitaria a que eles se inserissem (mesmo marginalmente) na rede extensa de fluxo (internacional) de mercadorias sem que precisassem abandonar seu local de origem. Para tanto, os canais para o fluxo dos bens artesanais deve ser construído ligando os diferentes agentes que compõem o processo que vai da produção ao consumo (nacional e mesmo internacional) nos moldes do que ocorreu (e ainda ocorre) em termos de ampliação da malha viária e aérea com fins de facilitar os deslocamentos e incremento da rede de informações, o que também é imprescindível. Tratam-se de duas ordens simultâneas de canais: o desenvolvimento dos meios de transporte para a viagem dos bens, de modo a melhor inserir as regiões marginais; e a diminuição das distâncias que integram as cadeias de agentes, o que permite e facilita a estruturação dos negócios. Coordenadorias, ONGs, cooperativas, núcleos, universidades, SENAC, SESI funcionam como módulos de integração na rede (pontos intermediários) que, sem diminuir as distâncias físicas entre os pontos inicial e final da rede, diminuem as distâncias relacionais pela estruturação de cursos profissionalizantes, trabalhos de 


\section{Economia criativa: entre a moda e o artesanato}

consultoria, organização de eventos (como feiras de negócios, a exemplo do Senac Rio Fashion Business e da Mostra Nacional de Desenvolvimento Regional, este último de iniciativa do Ministério da Integração Nacional), dentre outros.

No que se refere ao artesanato têxtil "tradicional", seu consumo no Brasil ainda está vinculado ao exótico (de apelo turístico) e ao gosto pelo hippie. Em âmbito internacional, entretanto, o artesanato brasileiro, compreendido como bem autêntico, por sua origem popular, torna-se igualmente produto de luxo, por sua unicidade e trabalho (manual) que envolve. $\mathrm{O}$ artesanal de maior apelo dentro do Brasil, mas com possibilidades de consideráveis ecos no mercado global, ou seja, o uso da força artesanal de modo renovado, como afirmou Hadida, no citado debate de abertura ao SPFW, vem sendo o artesanal entre aspas, que se distingue, em grande medida, do artesanato têxtil produzido nos confins do Brasil por estar mais adaptado à dinâmica da moda, seja pela liberdade criativa, seja pela possibilidade de utilização de maquinário de ponta para produção em mais ampla escala e em tempo menor, seja pelo cuidado com questões de qualidade de materiais e acabamento. Em outros termos, tratam-se de peças que podem, inclusive, apenas aparentar ser artesanais (no sentido de envolver trabalho manual), mas que foram industrialmente confeccionadas, cujos criadores não estão atados a uma concepção de reprodução do trabalho intergeracionalmente transmitido, e sim de vinculação com a inovação no fazer e no que é feito como fator crucial ao estabelecimento de negócios. É o caso de Lucas Nascimento, 30 anos, natural de Bonito (MS), que aprendeu a tricotar aos 11 anos com a mãe e fez cursos especializados na University of the Arts London e no London College of Art. Na capital inglesa, trabalhou no atelier de Sid Bryan, especialista em tricô que cria para as marcas Lanvin, Fendi e Giles. No Brasil, Lucas Nascimento criou para as marcas Ellus, 2nd Floor, Juliana Jabour, dentre outros. No momento, o estilista trabalha para criar os tricôs para a Ghetz, em Socorro (SP).

O motivo do sucesso: em suas coleções a trama tradicional, por anos associada à imagem da velhinha em uma cadeira de balanço com as agulhas e o novelo de lã no colo, é transformada em algo novo e fresh. A modelagem é conceitual e, graças à tecnologia, suas peças têm texturas complexas e efeitos surpreendentes. (MERLO, 2011, p. 174).

Em sua primeira coleção, apresentada no São Paulo Fashion Week, em janeiro de 2011, segundo Merlo, Lucas Nascimento estabeleceu uma parceria com o artista plástico inglês Bruce Ingram. O artista plástico fez colagens especialmente para a Ghetz, depois os trabalhos foram fotografados e as imagens foram transferidas para o computador. A partir daí, foram feitas as texturas, desenvolvidas nas máquinas alemãs da fábrica.

Sua coleção para o inverno 2011 foi elogiadíssima: mistura blocos de texturas e espessuras diferentes - alguns fios dez vezes mais grossos que os outros. Seu objetivo era buscar a leveza e uma noção de 360 graus da peça, com costuras 
apenas na lateral e nas costas. (...) “O mais interessante do tricô é a possibilidade de conseguir tudo. Não há barreiras. Dá pra criar qualquer coisa" (MERLO, 2011, p. 175).

Por outro lado, com o crescimento do debate ecológico, é possível observar que trabalhos artesanais fazendo uso de materiais como o plástico ou que enfatizam a reciclagem, na produção de moda, têm ganhado espaço e, junto com o desejo de personalização das peças, têm conferido maior notoriedade à produção artesanal no país. Tanto estes produtos chamados ecologicamente corretos, como aqueles aparentemente artesanais estão intimamente ligados à dinâmica da moda pela tônica na novidade, em ambos os casos, e pela possibilidade de produção em maior escala e velocidade, mais especificamente no segundo caso. No que se refere à artesania "tradicional", sua marca acaba sendo a pouca inventividade e a produção mais lenta, o que parece ainda favorecer sua comercialização, em primeiro lugar, em contexto internacional (onde é novidade), ou o estímulo ao artesanato de segunda ordem pela rubrica de responsabilidade social, também incentivada governamentalmente através de dedução de impostos. Em outros termos, o consumidor brasileiro, em geral, parece se sentir pouco atraído por esses produtos.

A empresa pernambucana Fátima Rendas, fundada em 1975, busca articular artesanato e moda, segundo seu material de divulgação, com produtos comercializados nacional e internacionalmente. A história de 38 anos dessa empresa, que se mantém como empresa familiar de produção de roupas e artigos para o lar a partir do uso da renda Renascença, evidencia o tipo de público que há tempos se volta para o artesanal, uma vez que a maior parte de suas lojas, no Brasil, está situada em aeroportos (quatro de suas seis filiais). Por outro lado, reportagens em revistas de moda insistem em afirmar que "o Brasil está na moda" e estar na moda parece significar também a valorização e o reconhecimento do "artesanato tradicional brasileiro" como de bom gosto e passível de se apresentar como moda. Essas iniciativas, contudo, parecem, ao contrário, reafirmar a dificuldade de tal reconhecimento, o que evidencia uma espécie de descompasso entre o artesanato têxtil, fincado nos rincões do Brasil, e uma produção de moda voltada a brasileiros, a não ser no que toca a específicos e restritos nichos de mercado. É nesse sentido que o caso de Martha Medeiros se torna interessante para fins de discussão.

\section{Martha Medeiros: artesanato e moda}

Os trabalhos de Martha Medeiros, em Maceió, iniciaram-se com a confecção de bordados em peças de vestuário. Atualmente, a estilista, que se filiou à ABEST (Associação Brasileira de estilistas) em 2009, mantém ateliê e loja própria no bairro de Ponta Verde, em Maceió (AL), e no Jardins, em São Paulo (SP), com 


\section{Economia criativa: entre a moda e o artesanato}

comercialização de produtos no Brasil (em 20 pontos de vendas) e no exterior (Oriente Médio, EUA, Inglaterra, Portugal e Alemanha). Com avó professora de arte e seus próprios trabalhos artesanais, Martha Medeiros ganhou projeção quando, conhecedora do artesanato local, se associou a cooperativas de rendeiras do interior de Alagoas, às margens do Rio São Francisco. Tal ordem de associação é estimulada governamentalmente por incentivos fiscais e, sob a tônica da responsabilidade social, acaba por implicar em imagem positiva para a empresa por seu estímulo ao desenvolvimento de cidades e regiões periféricas.

Para fazer parte do time ético, uma marca precisa obedecer critérios de respeito às condições de trabalho, aos materiais utilizados na produção e valorizar o savoir-faire local - leia-se, o artesanato. Além de seguir à risca as convenções estabelecidas pela Organização Internacional do Trabalho, com a jornada semanal de, no máximo, 48 horas e uma remuneração justa, uma empresa deve valorizar a mão de obra local, respeitar os costumes de cada comunidade e investir em melhorias infra-estruturais para a população. No caso da matéria-prima e do processo produtivo, a indústria têxtil precisa favorecer o uso de produtos menos prejudiciais ao meio-ambiente (LUMA, 2011, p. 66).

Uma evidência da resposta esperada pela associação da marca às cooperativas são as fotos e a indicação da participação das rendeiras nos catálogos e site da marca. São, segundo as informações divulgadas no site, cerca de 250 artesãs que trabalham na confecção das rendas Renascença, filé, Richelieu, bilro e da renda Boa Noite, hoje confeccionada apenas na Ilha do Ferro, a $320 \mathrm{~km}$ de Maceió.

Do mandacaru, cactos típicos da região, saem os espinhos que, nas mãos das artesãs, se transformam em alfinetes que servem como guias para a trama das rendas de Bilro. A renda Renascença é inteiramente feita com agulha e linha da mesma espessura da linha de pregar botões. Um vestido de Renascença pode exigir sete, oito meses de trabalho das mãos de uma única rendeira.

Foi desta forma que Martha Medeiros uniu a riqueza do trabalho feito à mão à sofisticação da alta costura (www.marthamedeiros.com.br, 26 de maio de 2011).

Para compor um "trabalho artesanal apresentado com uma linguagem contemporânea", de acordo com os termos expressos no site da estilista, o processo de trabalho de Martha Medeiros a transmuta numa espécie de artesã de segunda ordem, pois seu trabalho se dá sobre uma base artesanal já constituída. As artesãs do interior de Alagoas tecem a renda num formato retangular, como se se tratasse de uma estampa sobre o tecido a ser utilizado nas criações da estilista que pode, assim, utilizar o tecido de diferentes modos, inclusive articulando fragmentos de diferentes peças (motivos e cores) numa confecção única. É deste modo que a estilista se apresenta como artesã e também como criadora de moda, por seu trabalho ser "mais livre", não estar apegado aos ditames de uma suposta tradição, 
entendida como quase reprodução do mesmo, com pouca abertura e motivação às inovações 5 .

Deste modo, ainda que as rendas se apresentem em diferentes peças, uma hierarquia de valores se estabelece pela ordem da criatividade, elemento que distingue as diferentes artesanias em jogo, permitindo que a estilista se sobreponha em termos de prestígio e rendimento às 250 mulheres que a auxiliam. Assim, comparecem nas araras vestidos, caftans, saias, blusas, sapatos e bolsas com rendas. Destaque-se que as rendeiras também tecem roupas completas e emprestam seu nome singular a cada vestido que tecem, numa espécie de assinatura da obra, mesmo subordinada à assinatura maior em que se constitui o nome da marca. É o tamanho da equipe que permite maior velocidade às produções, que ganha ares de alta-costura. Trata-se de "DNA nacional e qualidade internacional". Os modelos são contemporâneos, há cuidados especiais com acabamento e modelagem e junto, por exemplo, à renda renascença brasileira, são usados, segundo informações divulgadas no site da estilista, apenas materiais considerados nobres, como musseline de seda, tule e renda francesa, barbatana de silicone alemã e crinol suíço.

De qualquer forma, pode-se observar que a inserção de Martha Medeiros no circuito nacional e internacional de moda teve como um de seus momentos a sua saída de Maceió para abertura de ateliê em São Paulo, o que evidencia a relação precária entre fluxo de mercadorias e fixação de gente. As artesãs permanecem no interior de Alagoas; suas peças viajam ao encontro da reelaboração da estilista e da redistribuição dessas peças finalizadas para diferentes estados e países, mas não em detrimento da fixação também da estilista, e sim de sua movimentação ainda para o centro relacional e de visibilidade em que se constituiu São Paulo, sede dos maiores eventos e negócios de moda no Brasil. Isso evidencia a importância ainda do centro relacional, que se mantém enquanto tal. A inserção das rendeiras é, portanto, marginal, periférica na rede, gerando discrepâncias consideráveis na distribuição dos rendimentos e do prestígio, ainda que sejam perceptíveis as alterações econômicas, de cotidiano e de relação com o trabalho na vida desses grupos, fazendo, inclusive, com que o artesanato passe a figurar como atividade econômica principal das famílias e incluindo a participação masculina no processo de trabalho - uma vez que, historicamente, o artesanato se constituiu como atividade feminina.

\footnotetext{
${ }^{5}$ Certas intervenções de agentes de cultura, através de cursos profissionalizantes, acabam por intervir no processo criativo ao estimular, por exemplo, o uso de cores em conformidade com as tendências divulgadas para o período. No entanto, a menção feita aqui à pouca abertura às inovações refere-se ao possível movimento interno, espontâneo dos próprios artesãos em relação a seus produtos.
} 


\section{Economia criativa: entre a moda e o artesanato}

\section{Considerações finais}

O panorama da produção e consumo de artesanato no Brasil atualmente se mostra bastante diversificado e em processo de mudanças. Ao mesmo tempo em que percebemos grupos de produção que mantêm os costumes de formatos, cores, texturas e processo produtivo, vemos, igualmente, nomes se estabelecerem a partir de produção artesanal intimamente ligada a uma concepção de moda enquanto novidade e produção em larga escala, o que permite um rol mais amplo de inovações e conta com o apoio de maquinário de tecnologia avançada na produção do aparentemente artesanal. Todavia, o "lugar" ocupado por essas diversas ordens de artesãos, em seu trabalho individual ou coletivo, só pode ser compreendido se levar em consideração as características e gosto dos consumidores brasileiros - ou seja, o tipo de visão e interpretação que têm a respeito do artesanato em geral e, especificamente, daquilo que, para fins deste texto, foi denominado artesanato "tradicional". É nesse sentido que se pode compreender o reconhecimento do trabalho de Martha Medeiros e o porquê de tantos artesãos que dominam a técnica da renda de Bilros e da renda Renascença permanecerem em situação de precariedade econômica.

Martha Medeiros, bem como Lucas Nascimento, trabalham a partir da lógica da moda, da qual a maior parte dos artesãos está fora. No caso de Martha Medeiros, há a reprodução das diferenças entre estilista e costureiros (no caso, rendeiras), ou seja, entre aquele que se mantém como trabalhador intelectual, por sua criatividade, e aqueles que têm a tarefa de executores da obra. Trata-se da distinção que permitiu, no século XIX, o surgimento da figura do estilista e o pleito ao reconhecimento da moda como arte, com a assinatura dos croquis pelos criadores, a fim de individualizar e registrar a obra. Se Martha Medeiros se coloca como artesã de segunda ordem, por seu trabalho criativo e manual, Lucas Nascimento se distingue pelo elemento criativo, mas também pelo uso de tecnologia avançada na criação do artesanal e do aparentemente artesanal, evidenciando, ambos, a complexidade da discussão sobre o artesanato no contexto atual, especialmente em sua relação com a moda. Destaque-se, aí, o leque de desafios postos à operacionalização de uma ideia de economia criativa, no Brasil, e o fundamental papel do Governo em termos de medidas que viabilizem, por um lado, a descentralização da produção, do consumo e da profissionalização e, por outro, a diminuição das distâncias relacionais e o trânsito dos bens. 


\section{Referências bibliográficas}

GERALDINI, Mayara. Aquecimento Fashion Rio: de onde veio e para onde vai a semana moda carioca. In: http://moda.ig.com.br/noticia/2008/06/06/aquecimento_fashion_rio_de... Acesso em: 28/01/2009.

HERCHCOVITCH, Alexandre. Cartas a um jovem estilista: a moda como profissão. Rio de Janeiro: Elsevier, 2007.

KALIL, Gloria. Economia criativa: moda e design. In: http://chic.ig.com.br/alochics/noticia/economia-criativa-moda-e-design, 09/06/2010. Acesso em: 20/09/2012.

LUMA, Mayara. Ético: o novo básico. Vogue (suplemento). São Paulo, Edições Globo Condé Nast, n. 391, p. 66-7, março, 2011.

MERLO, Paula. Tramas da arte. Vogue. São Paulo, Edições Globo Condé Nast, n. 391, p. 174, março, 2011.

MINISTÉRIO DA CULTURA. Plano da Secretaria da Economia Criativa: políticas, diretrizes e ações, 2011-2014. 2.ed. Brasília: Ministério da Cultura, 2011. 156p.

SANTOS, Milton, SILVEIRA, María Laura. O Brasil: território e sociedade no início do século XXI. 9.ed. Rio de Janeiro: Record, 2006. 480p.

SARAIVA, Enrique. Política pública, política cultural, indústrias culturais e indústrias criativas. In: MINISTÉRIO DA CULTURA. Plano da Secretaria da Economia Criativa: políticas, diretrizes e ações, 2011-2014. 2.ed. Brasília: Ministério da Cultura, 2011. p. 93-96.

SPITZ, Clarice. Famílias gastam $7,9 \%$ do orçamento com cultura, aponta estudo. Folha Online. In: www1.folha.uol.com.br/folha/ilustrada/ult90u66497.1html. Acesso em: 29 de novembro de 2006.

http://www.abest.com.br/abest/abest.php?lang=pt, acesso em 20 de outubro de 2012.

www.fatimarendas.com.br, acesso em 26 de maio de 2011.

www.marthamedeiros.com.br, acesso em 26 de maio de 2011.

Latitude, vol. 6, n², pp.221-239, 2012. 